\title{
Editorial
}

\section{Fifty years of clinical and research studies for childhood renal tumors within the International Society of Pediatric Oncology (SIOP) *}

Norbert Graf ${ }^{1}$, Christophe Bergeron ${ }^{2}$, Jesper Brok ${ }^{3}$, Beatriz de Camargo ${ }^{4}$, Tanzina

Chowdhury $^{5}$, Rhoikos Furtwängler ${ }^{1}$, Manfred Gessler ${ }^{6}$, Jan Godzinski ${ }^{7}$, Kathy PritchardJones $^{8}$, Gema Ramirez ${ }^{9}$, Christian Rübe ${ }^{10}$, Bengt Sandstedt ${ }^{11}$, Jens-Peter Schenk ${ }^{12}$, Filippo Spreafico $^{13}$, Hélène Sudour-Bonnange ${ }^{14}$, Harm van Tinteren ${ }^{15}$, Arnauld Verschuur ${ }^{16}$, Gordan Vujanic $^{17}$, Marry M. van den Heuvel-Eibrink ${ }^{15}$

${ }^{1}$ Department of Pediatric Oncology and Hematology, Saarland University, D-66421 Homburg, Germany; norbert.graf@uks.eu, rhoikos.furtwaengler@uks.eu

${ }^{2}$ Department of Paediatric Haemato-Oncology, Centre Léon Bérard, Lyon, France;

${ }^{3}$ Department of Pediatric Oncology and Hematology, Rigshospitalet, 2100 Copenhagen,

Denmark; jesper.sune.brok@ regionh.dk

${ }^{4}$ Research Center, Instituto Nacional do Cancer, Rio de Janeiro, Brazil;

bdecamar@terra.com.br

${ }^{5}$ Department of Haematology and Oncology, Great Ormond Street Hospital for Children NHS Foundation Trust, London, UK; tanzina.chowdhury@gosh.nhs.uk

${ }^{6}$ Theodor-Boveri-Institute/Biocenter and Comprehensive Cancer Center Mainfranken, University of Würzburg, Würzburg, Germany; gessler@biozentrum.uni-wuerzburg.de ${ }^{7}$ Department of Pediatric Surgery, Marciniak Hospital, Fieldorfa 2 and Department of Paediatric Traumatology and Emergency Medicine,Wroclaw Medical University, ul. Bujwida 44a, 54-049 Wroclaw, Poland; jgodzin@wp.pl

${ }^{8}$ Developmental Biology and Cancer Research and Teaching Department, University College London Great Ormond Street Institute of Child Health, University College London, London, UK; k.pritchard-jones@ucl.ac.uk

${ }^{9}$ Department of Paediatric Oncology, Hospital Universitario Virgen del Rocío, Seville, Spain; gemal.ramirez.sspa@juntadeandalucia.es

${ }^{10}$ Department of Radiation Oncology, Saarland University, D-66421 Homburg, Germany; christian.ruebe@uks.eu

${ }^{11}$ Childhood Cancer Research Unit, Karolinska Institutet, Stockholm, Sweden; bengt.Sandstedt@ki.se 
${ }^{12}$ Section Pediatric Radiology, Department for Diagnostic and Interventional Radiology, University Hospital Heidelberg, Im Neuenheimer Feld 430, 69120 Heidelberg, Germany; jens-peter.schenk@med.uni-heidelberg.de

${ }^{13}$ Department of Medical Oncology and Hematology, Pediatric Oncology Unit, Fondazione IRCCS Istituto Nazionale dei Tumori, 20133 Milan, Italy;

filippo.spreafico@istitutotumori.mi.it

${ }^{14}$ Centre Oscar Lambret, Department of Children and AJA Oncology, Lille, France; hsudour@o-lambret.fr

${ }^{15}$ Princess Máxima Center for Pediatric Oncology, Heidelberglaan 25, 3584 CS Utrecht, The Netherlands; m.m.vandenheuvel-eibrink@ prinsesmaximacentrum.nl, H.vanTinteren@prinsesmaximacentrum.nl

${ }^{16}$ Department of Pediatric Oncology, Hôpital d'Enfants de la Timone, Marseille, France; arnauld.verschuur@ap-hm.fr

${ }^{17}$ Department of Pathology, Sidra Medicine and Weill Cornell Medicine - Qatar, Doha, Qatar; gvujanic@sidra.org

\section{Corresponding author:}

Prof. Dr. Norbert Graf

Department of Pediatric Oncology and Hematology Saarland University, 66421 Homburg, Germany

E-mail: norbert.graf@uks.eu

Tel: $\quad 0049(0) 68411628397$

Fax: $0049(0) 6841161728397$

*Dedicated to Jan de Kraker, chair of SIOP RTSG from 1993-2008 
Nephroblastoma or Wilms tumor (WT) was one of the first childhood cancers shown to be curable with $\sim 10-15 \%$ survival even when treated with surgery alone and it was also the first solid tumor where lung metastases were successfully treated with the addition of actinomycin and radiotherapy in early 1960s. Shortly after, two study groups - the International Society of Paediatric Oncology (SIOP) in Europe, and the National Wilms Tumor Study group (NWTSG) in Northern America - were formed and started running prospective and randomized trials intended to find optimal treatment for children with WT. At the initial SIOP meetings held in Madrid (1969), Lyon (1970) and Mainz (1971), the "purpose, scope and outline of a prospective SIOP trial for WT was discussed and approved", ${ }^{1}$ and in 1971 the first patient was enrolled in the SIOP-1 study. Since then, seven clinical studies and randomized trials have been completed by SIOP (Fig 1). SIOP focused on the relative merits of pre-nephrectomy treatment in contrast to NWTSG pursuing immediate surgery. The recently started SIOP-RTSG 2016 UMBRELLA study is recruiting patients from the most of Europe and from the other continents.

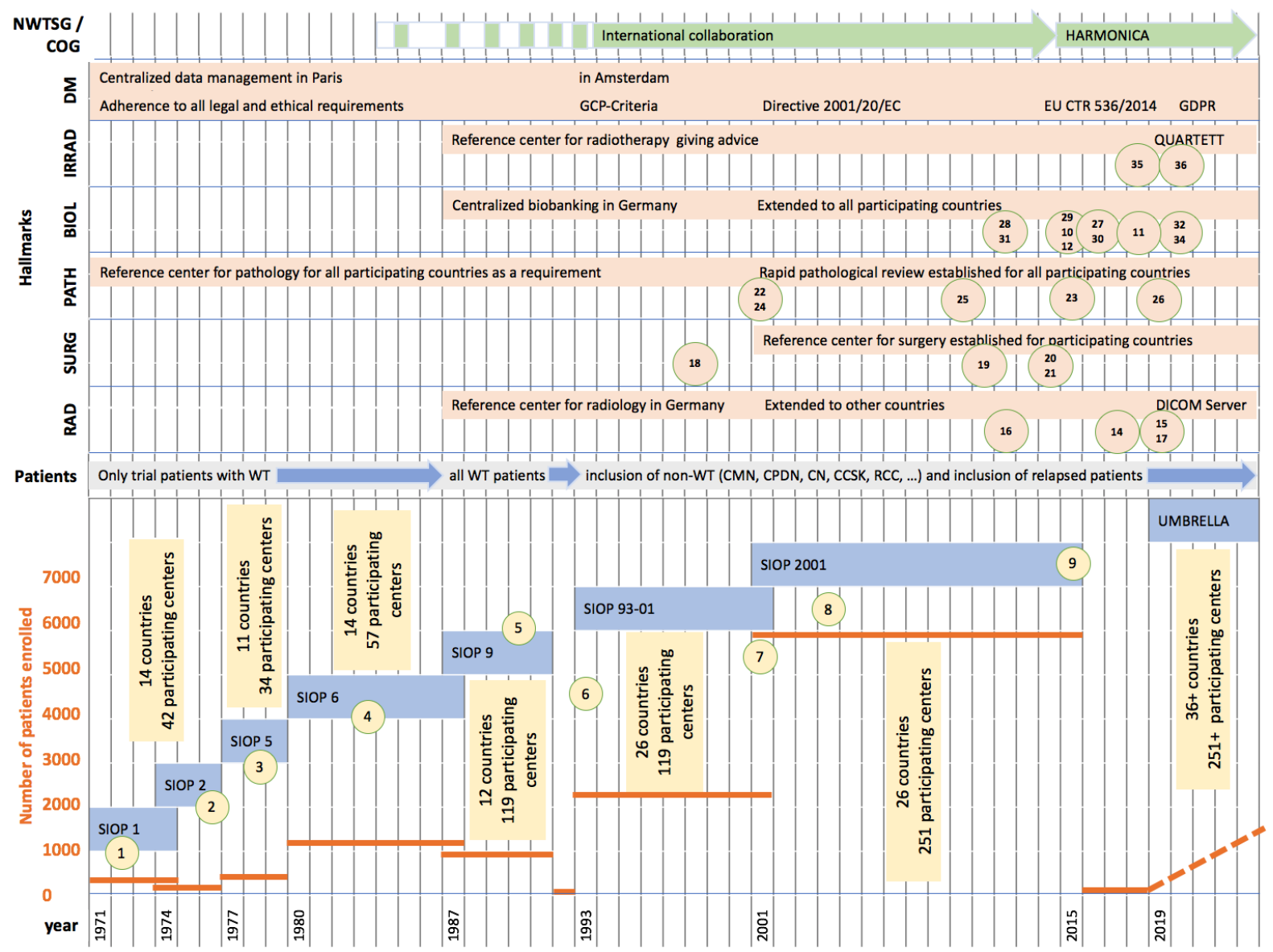

Figure 1: Clinical trials for childhood renal tumors over time. Numbers in circles refer to the corresponding references; GCP: Good Clinical Practice; 2001/20/EC: Clinical Trial Directive; CTR: Clinical Trial Regulation; GDPR: General Data Protection Regulation; QUARTETT: Platform for Radiotherapy Consultation; WT: Wilms tumor; MN: congenital mesoblastic nephroma; CPDN: cystic partially differentiated nephroblastoma; CN: cystic nephroma; CCSK: clear cell sarcoma of the kidney; RCC: renal cell carcinoma

In the first three trials (SIOP 1, 2 and 5) the benefits of pre-operative treatment in WT were established. This approach resulted in safer operations with fewer tumor ruptures, and a favorable postoperative stage distribution allowing less treatment after surgery. ${ }^{2-4}$ The fourth 
trial (SIOP 6) was the first to introduce stratification according to stage and histology, determining a risk-adapted post-surgical treatment. ${ }^{5}$ Duration and intensity of chemotherapy was randomized in local stages building the basis for future trials, and less than $1 / 3$ of patients need to receive radiotherapy since. In parallel, a pilot study was completed for patients with metastatic tumors, showing that a 3-drug pre-operative chemotherapy regimen (vincristine, actinomycin and doxorubicin [AVD]) is efficient and allows omission of lung irradiation in $>70 \%$ of patients in complete remission after pre-operative chemotherapy and surgery. ${ }^{6}$ It was concluded that stratification of treatment according to risk factors could significantly limit acute and late toxicity and lead to $\sim 90 \%$ overall survival after 5 years for the entire group of WT patients. ${ }^{5}$ Four weeks of pre-operative chemotherapy in localized WT with vincristine and actinomycin (AV) was found to be the gold standard in SIOP-9. ${ }^{7}$ After SIOP 93-01 trial, postoperative chemotherapy in localized stage I intermediate risk WT (IR-WT) was reduced from 18 to 4 weeks of AV. ${ }^{8}$ As IR-WTs stage I account for $>50 \%$ of localized WTs, a majority of WTs is now cured with only 8 weeks of 2-drug AV chemotherapy (4 weeks pre- and 4 weeks post-operatively) and nephrectomy. Besides living with a solitary kidney after surgery, other long-term sequelae are negligible in most WT survivors receiving this minimal treatment. To further reduce late toxicities without compromising the high survival rates, in SIOP 2001 trial the use of anthracyclines was randomized in localized stage II and III IR-WTs. Overall survival rates were superimposable ( $\sim 95 \%)$ for patients who were treated with and without doxorubicin. ${ }^{9}$ Parallel molecular studies have identified numerous driver genes in WT and non-WTs, some being candidates for prognostic biomarkers or therapeutic leads. ${ }^{10-12}$

The current UMBRELLA study aims to facilitate the best possible diagnostics and treatment for all children and adolescents with renal tumors. By collecting and analysing biomaterial systematically, the goal is to find new biomarkers and better stratification parameters for future trials. ${ }^{13}$ Furthermore, for the subgroup of stage IV WT patients a randomized trial will explore whether a less toxic pre-operative chemotherapy with carboplatin, etoposide and vincristine is as effective as AVD. Another trial is prepared asking the question whether highly conformal radiotherapy is as effective as conventional regimens.

Since SIOP 93-01 trial patients with non-WTs are registered, and since UMBRELLA study specific guidelines are provided including diagnostic and treatment recommendations. In addition, guidelines for adult WT are given.

Although renal tumors in childhood are rare, $>10,000$ patients from over 260 centers across 36 countries have been enrolled and treated according to SIOP protocols (Fig. 1). As the number of centers participating in SIOP WT trials is increasing, the SIOP Renal Tumour Study Group (RTSG) Association was founded in 2021 (Fig. 2) to deal better with our main mission of increasing survival rates and reducing acute treatment toxicity and late effects in patients with renal tumors. SIOP-RTSG aims to offer the same standardized high-quality diagnostics and treatment to all patients, irrespectively of the tumor type, their socio-economic status or the geographic region where patients live. In this respect kidney cancer in childhood will serve as a paradigm for rare cancers, which is in line with the aspirations of both SIOP, and the WHO global initiative in childhood cancer. 


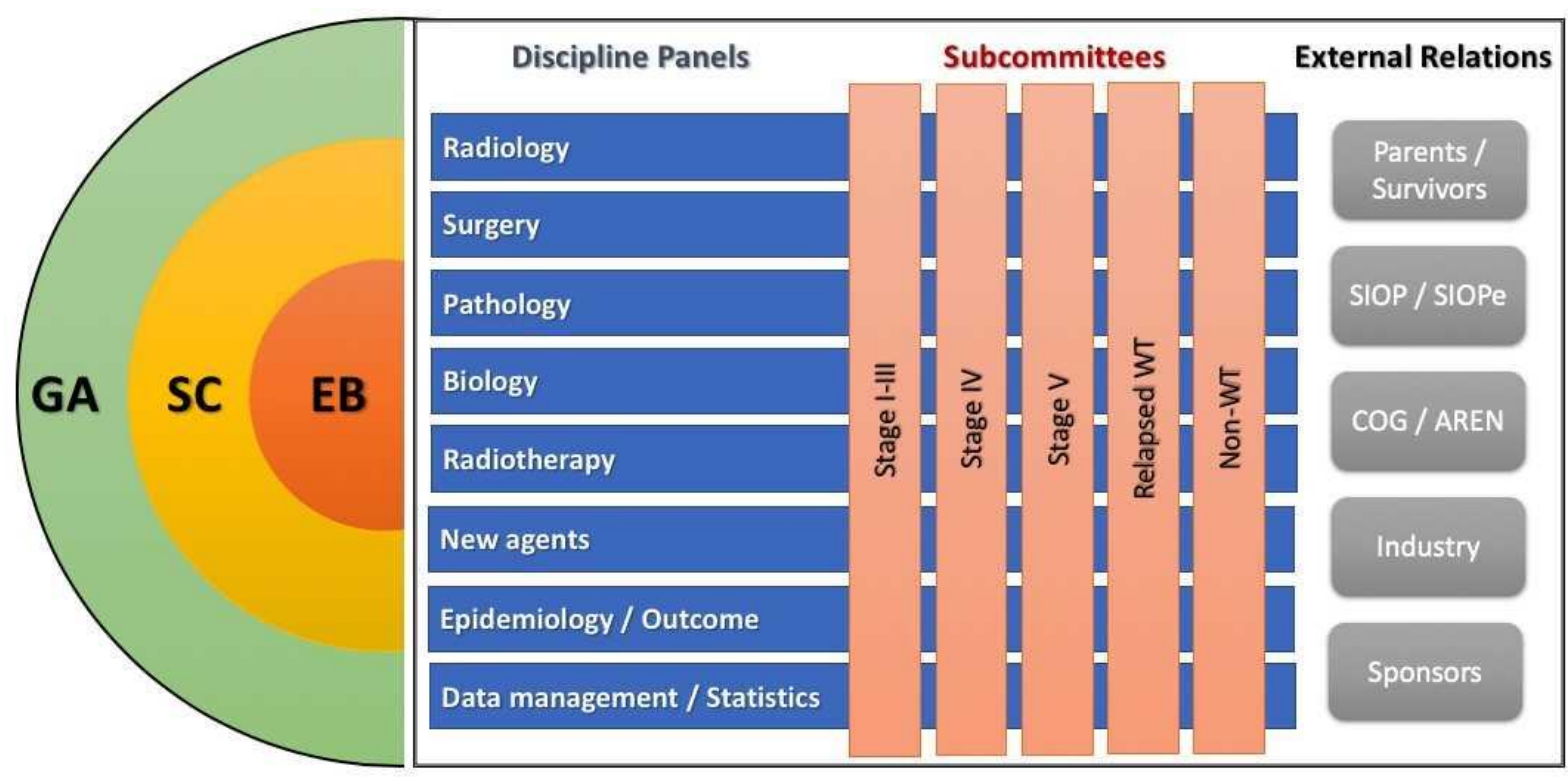

Figure 2: The structure and bodies of SIOP-RTSG. GA: General Assembly; SC: Steering Committee; EB: Executive Board; COG: Children's Oncology Group; AREN: Renal tumor trials in $C O G$.

All discipline panels and subcommittees have gathered enormous knowledge over time, from the trials and studies and from basic research. This was based on clinical, pathological and outcome data, but also on biomaterial and imaging data. For quality control reference centers for radiology, surgery, pathology and radiotherapy were set up and which contributed immensely to current knowledge in renal tumors in childhood. This knowledge from retrospective research projects was (Table 1) and will be prospectively validated in upcoming trials and studies.

\begin{tabular}{|c|c|c|}
\hline Discipline & Findings & Literature \\
\hline Radiology & $\begin{array}{l}\text { Diffusion weighted MRI is helpful in characterizing renal tumors } \\
\text { Outcome of patients with CT-only lung metastasis is inferior to no metastasis } \\
\text { Specific renal tumors require biopsy before preoperative chemotherapy }\end{array}$ & $\begin{array}{l}(14),(15) \\
(16) \\
(17)\end{array}$ \\
\hline Surgery & $\begin{array}{l}\text { Significant less tumor ruptures after preoperative chemotherapy } \\
\text { Less operative complications after preoperative chemotherapy } \\
\text { Metastasectomy is beneficial for outcome } \\
\text { Nephron sparing surgery (NSS) is possible in selected unilateral WTs } \\
\text { NSS is possible in 50\% on both sides in bilateral cases }\end{array}$ & $\begin{array}{l}(1),(3),(4) \\
(18) \\
(19) \\
(20) \\
(21)\end{array}$ \\
\hline Pathology & $\begin{array}{l}\text { SIOP histological risk-adapted classification of renal tumors } \\
\text { Diffuse anaplasia in WT is a high-risk tumor feature } \\
\text { Blastemal type after preoperative chemotherapy is a high-risk tumor } \\
\text { Complete necrotic tumors after preoperative chemotherapy are low-risk }\end{array}$ & $\begin{array}{l}(22) \\
(5) \\
(23),(24) \\
(24),(25),(26)\end{array}$ \\
\hline Biology & $\begin{array}{l}\text { 1q gain and other molecular markers are of prognostic relevance } \\
\text { miRNAs from blood and tumor tissue as potential biomarkers } \\
\text { Intra-tumoral heterogeneity is important to take into consideration } \\
\text { Spheroids and organoids from tumor tissue can be established }\end{array}$ & $\begin{array}{l}(27) \\
(28),(29),(10) \\
(30) \\
(31),(32),(33),(34)\end{array}$ \\
\hline Radiotherapy & $\begin{array}{l}\text { Postoperative irradiation is as beneficial for outcome as preoperative } \\
\text { Boost for positive lymph nodes is not needed } \\
\text { Consensus on flank target delineation for highly conformal radiotherapy }\end{array}$ & $\begin{array}{l}(2) \\
(35) \\
(36)\end{array}$ \\
\hline
\end{tabular}


Table 1: Most important findings by SIOP-RTSG.

The basis for the current UMBRELLA study is summarized in several reviews on Nephroblastoma, ${ }^{13,37,38}$ relapse treatment, ${ }^{39,40}$ pathology and biology, ${ }^{41}$ but also on different non-WTs. ${ }^{42-46}$

Over the last decades collaboration and exchange of knowledge between SIOP-RTSG and the Children's Oncology Group Renal Tumor Committee has developed resulting in a number of papers such as renal tumors of early age, ${ }^{47}$ a meta-analysis of high dose chemotherapy ${ }^{48}$ late relapses ${ }^{49}$ the advances of international collaboration $^{50}$ and new approaches to risk stratification for WT. ${ }^{51}$ In 2015 the task force HARMONICA (HARMONIzation and CollAboration for pediatric renal tumors) was established as an exchange platform, building on the expertise of both large study groups, enhancing international collaboration and supporting Young Investigators interested in renal tumors in childhood.

Based on all these efforts we hope that the goal of SIOP-RTSG to cure every child with a renal tumor will become reality. 


\section{References}

1. Voûte PA, Lemerle J. Trial of therapy and prospective study of nephroblastoma. Pediatrics. 1972;49:638-639.

2. Lemerle J, Voûte PA, Tournade MF, et al. Preoperative versus postoperative radiotherapy, single versus multiple courses of Actinomycin $\mathrm{D}$, in the treatment of Wilms' tumor. Cancer. 1976;38:647-54.

3. Voute P, Tournade M, Lemerle J, et al. Results of studies conducted by the International Society of Paediatric Oncology (SIOP) from 1971-1978 concerning Wilms' tumor. Abstracts of the tenth Meeting of the International Society of Paediatric Oncology (SIOP). 1978;3-5 (abstract 14).

4. Lemerle J, Voute PA, Tournade MF, et al. Effectiveness of preoperative chemotherapy in Wilms' tumor: results of an International Society of Paediatric Oncology (SIOP) clinical trial. J Clin Oncol. 1983;1:604-609.

5. Tournade MF, Com-Nougué C, Voûte PA, et al. Results of the Sixth International Society of Pediatric Oncology Wilms' Tumor Trial and Study: a risk-adapted therapeutic approach in Wilms' tumor. J Clin Oncol. 1993;11:1014-1023.

6. de Kraker J, Lemerle J, Voûte PA, et al.. Wilms' tumor with pulmonary metastases at diagnosis: the significance of primary chemotherapy. J Clin Oncol. 1990;8:1187-1190.

7. Tournade MF, Com-Nougué C, de Kraker J, et al. Optimal duration of preoperative therapy in unilateral and nonmetastatic Wilms' tumor in children older than 6 months: Results of the Ninth International Society of Pediatric Oncology Wilms' Tumor Trial and Study. J Clin Oncol. 2001;19:488-500.

8. de Kraker J, Graf N, van Tinteren H, et al. Reduction of postoperative chemotherapy in children with stage I intermediate-risk and anaplastic Wilms' tumour (SIOP 93-01 trial): a randomised controlled trial. Lancet. 2004;364:1229-1235.

9. Pritchard-Jones K, Bergeron C, de Camargo B, et al. Omission of doxorubicin from the treatment of stage II-III, intermediate-risk Wilms' tumour (SIOP WT 2001): an openlabel, non-inferiority, randomised controlled trial. Lancet. 2015;386:1156-1164.

10. Wegert J, Ishaque N, Vardapour R, et al. Mutations in the SIX1/2 pathway and the DROSHA/DGCR8 miRNA microprocessor complex underlie high-risk blastemal Type Wilms tumors. Cancer Cell. 2015;27:298-311.

11. Wegert J, Vokuhl C, Collord G, et al. Recurrent intragenic rearrangements of EGFR and BRAF in soft tissue tumors of infants. Nature Communications. 2018;9:2378.

12. Williams RD, Chagtai T, Alcaide-German M, et al. Multiple mechanisms of MYCN dysregulation in Wilms tumour. Oncotarget. 2015;6:7232-7243.

13. van den Heuvel-Eibrink MM, Hol JA, Pritchard-Jones K, et al. Position paper: Rationale for the treatment of Wilms tumour in the UMBRELLA SIOP-RTSG 2016 protocol. Nature Reviews Urology. 2017;14:743-752.

14. Littooij AS, Sebire NJ, Olsen ØE. Whole-tumor apparent diffusion coefficient measurements in nephroblastoma: Can it identify blastemal predominance? J Magn Resonan Imag. 2017;45:1316-1324.

15. Hötker AM, Lollert A, Mazaheri Y, et al. Diffusion-weighted MRI in the assessment of nephroblastoma: results of a multi-center trial. Abd Radiol. 2020;45:3202-3212.

16. Smets AMJB, van Tinteren H, Bergeron C, et al. The contribution of chest CT-scan at diagnosis in children with unilateral Wilms' tumour. Results of the SIOP 2001 study. Eur J Cancer 2012;48:1060-1065.

17. Brisse HJ, de la Monneraye Y, Cardoen L, et al. From Wilms to kidney tumors: which ones require a biopsy? Pediatr Radiol. 2020;50:1049-1051.

18. Godzinski J, Tournade M, de Kraker J, et al. Rarity of surgical complications after postchemotherapy nephrectomy for nephroblastoma. Experience of the International 
Society of Paediatric Oncology - Trial and Study "SIOP-9." Eur J Pediatr Surg. 1998;8:83-86.

19. Warmann SW, Furtwängler R, Blumenstock G, et al. Tumor biology influences the prognosis of nephroblastoma patients with primary pulmonary metastases. Ann Surg. 2011;254:155-162.

20. Wilde JCH, Aronson DC, Sznajder B, et al. Nephron sparing surgery (NSS) for unilateral Wilms tumor (UWT): the SIOP 2001 experience. Pediatr Blood Cancer. 2014;61:2175-2179.

21. Fuchs J, Szavay P, Seitz G, et al. Nephron sparing surgery for synchronous bilateral nephroblastoma involving the renal hilus. J Urol. 2011;186:1430-1436.

22. Vujanic GM, Sandstedt B, Harms D, et al. Revised International Society of Paediatric Oncology (SIOP) working classification of renal tumors of childhood. Med Pediatr Oncol. 2002;38:79-82.

23. van den Heuvel-Eibrink MM, van Tinteren H, Bergeron C, et al. Outcome of localised blastemal-type Wilms tumour patients treated according to intensified treatment in the SIOP WT 2001 protocol, a report of the SIOP Renal Tumour Study Group (SIOPRTSG). Eur J Cancer. 2015;51:498-506.

24. Weirich A, Leuschner I, Harms D, et al. Clinical impact of histologic subtypes in localized non-anaplastic nephroblastoma treated according to the trial and study SIOP9/GPOH. Ann Oncol. 2001;12:311-319.

25. Vujanic GM, Sandstedt B. The pathology of Wilms' tumour (nephroblastoma): the International Society of Paediatric Oncology approach. J Clin Pathol. 2010;63:102109.

26. Vujanic GM, D'Hooghe E, Popov SD, et al. The effect of preoperative chemotherapy on histological subtyping and staging of Wilms tumors: The United Kingdom Children's Cancer Study Group (UKCCSG) Wilms tumor trial 3 (UKW3) experience. Pediatr Blood Cancer. 2019;66:e27549.

27. Chagtai T, Zill C, Dainese L, et al. Gain of 1q as a prognostic biomarker in Wilms tumors (WTs) treated with preoperative chemotherapy in the International Society of Paediatric Oncology (SIOP) WT 2001 Trial: A SIOP Renal Tumours Biology Consortium Study. J Clin Oncol. 2016;34:3195-3203.

28. Schmitt J, Backes C, Nourkami-Tutdibi N, et al. Treatment-independent miRNA signature in blood of wilms tumor patients. BMC Genomics. 2012;13:379.

29. Ludwig N, Nourkami-Tutdibi N, Backes C, et al. Circulating serum miRNAs as potential biomarkers for nephroblastoma. Pediatr Blood Cancer. 2015;62:1360-1367.

30. Cresswell GD, Apps JR, Chagtai T, et al. Intra-tumor genetic heterogeneity in Wilms tumor: Clonal evolution and clinical implications. EBioMedicine. 2016;9:120-129.

31. Wegert J, Bausenwein S, Roth S, et al. Characterization of primary Wilms tumor cultures as an in vitro model. Genes, Chromosomes Cancer. 2012;51:92-104.

32. Ooms AHAG, Calandrini C, de Krijger RR, et al. Organoid models of childhood kidney tumours. Nature Reviews Urology. 2020;17:313.

33. Calandrini C, Schutgens F, Oka R, et al. An organoid biobank for childhood kidney cancers that captures disease and tissue heterogeneity. Nature Communications. 2020;11:1310.

34. Wegert J, Zauter L, Appenzeller S, et al. High-risk blastemal Wilms tumor can be modeled by 3D spheroid cultures in vitro. Oncogene. 2020;39:849-861.

35. Dávila Fajardo R, Oldenburger E, Rübe C, et al. Evaluation of boost irradiation in patients with intermediate-risk stage III Wilms tumour with positive lymph nodes only: Results from the SIOP-WT-2001 Registry. Pediatr Blood Cancer. 2018;65:e27085.

36. Janssens GO, Melchior P, Mul J, et al. The SIOP-Renal Tumour Study Group consensus statement on flank target volume delineation for highly conformal 
radiotherapy. Lancet Child Adolescent Health. 2020;4:846-852.

37. Spreafico F, Dalissier A, Pötschger U, et al. High dose chemotherapy and autologous hematopoietic cell transplantation for Wilms tumor: a study of the European Society for Blood and Marrow Transplantation. Bone Marrow Transplant. 2020;55:376-383.

38. Pasqualini C, Furtwängler R, van Tinteren H, et al. Outcome of patients with stage IV high-risk Wilms tumour treated according to the SIOP2001 protocol: A report of the SIOP Renal Tumour Study Group. Eur J Cancer. 2020;128:38-46.

39. Brok J, Lopez-Yurda M, Tinteren HV, et al. Relapse of Wilms' tumour and detection methods: a retrospective analysis of the 2001 Renal Tumour Study Group-International Society of Paediatric Oncology Wilms' tumour protocol database. Lancet Oncol. 2018;19:1072-1081.

40. Brok J, Mavinkurve-Groothuis AMC, Drost J, et al. Unmet needs for relapsed or refractory Wilms tumour: Mapping the molecular features, exploring organoids and designing early phase trials - A collaborative SIOP-RTSG, COG and ITCC session at the first SIOPE meeting. Eur J Cancer. 2021;144:113-122.

41. Vujanic GM, Gessler M, Ooms AHAG, et al. The UMBRELLA SIOP-RTSG 2016 Wilms tumour pathology and molecular biology protocol. Nature Reviews Urology. 2018;15:693-701.

42. Gooskens SL, Houwing ME, Vujanic GM, et al. Congenital mesoblastic nephroma 50 years after its recognition: A narrative review. Pediatr Blood Cancer. 2017;64:e26437.

43. van Peer SE, Pleijte CJH, de Krijger RR, et al. Clinical and molecular characteristics and outcome of cystic partially differentiated nephroblastoma and cystic nephroma: A narrative review of the literature. Cancers. 2021;13:997.

44. Gooskens SL, Graf N, Furtwängler R, et al. Rationale for the treatment of children with CCSK in the UMBRELLA SIOP-RTSG 2016 protocol. Nature Reviews Urology. 2018;15:309-319.

45. Beek JN, Hol JA, Coulomb-l'Hermine A, et al. Characteristics and outcome of pediatric renal cell carcinoma patients registered in the International Society of Pediatric Oncology SIOP 93-01, 2001 and UK-IMPORT database: A report of the SIOP-Renal Tumor Study Group. Int J Cancer. 2021;148:2724-2735.

46. Nemes K, Bens S, Kachanov D, et al. Clinical and genetic risk factors define two risk groups of extracranial malignant rhabdoid tumours (eMRT/RTK). Eur J Cancer. 2021;142:112-122.

47. van den Heuvel-Eibrink MM, Grundy P, Graf N, et al. Characteristics and survival of 750 children diagnosed with a renal tumor in the first seven months of life: A collaborative study by the SIOP/GPOH/SFOP, NWTSG, and UKCCSG Wilms tumor study groups. Pediatr Blood Cancer. 2008;50:1130-1134.

48. Ha TC, Spreafico F, Graf N, et al. An international strategy to determine the role of high dose therapy in recurrent Wilms' tumour. Eur J Cancer. 2013;49:194-210.

49. Malogolowkin MH, Spreafico F, Dome JS, et al. Incidence and outcomes of patients with late recurrence of Wilms' tumor. Pediatr Blood Cancer. 2013;60:1612-1615.

50. Dome JS, Graf N, Geller JI, Fernandez C V., Mullen EA, Spreafico F, et al. Advances in Wilms tumor treatment and biology: Progress through international collaboration. $J$ Clin Oncol. 2015;33:2999-3007.

51. Nelson M V, van den Heuvel-Eibrink MM, Graf N, Dome JS. New approaches to risk stratification for Wilms tumor. Curr Opin Pediatr. 2021;33:40-48. 